\title{
Calculations of $\mathrm{ZnII} 3 d^{9} 4 s 5 s$ and $\mathrm{Ag} / 4 d^{9} 5 s 6 s$, and Some New Levels in these Spectra
}

\author{
William C. Martin and Jack Sugar \\ Institute for Basic Standards, National Bureau of Standards, \\ Washington, D.C. 20234
}

(August 28, 1969)

\begin{abstract}
Results of intermediate-coupling calculations are given for $\mathrm{Zn}$ II $3 d^{9} 4 s 5 s$ and Ag I $4 d^{9} 5 s 6 s$. A $\left[\left(4 d^{9}\right) J_{1},(5 s 6 s) J_{\mathrm{II}}\right] J$ coupling scheme is appropriate for the latter. New $3 d^{9} 4 s\left({ }^{3} \mathrm{D}\right) 5 s^{2} \mathrm{D}_{21 / 2}$ and $3 d^{9} 4 s\left({ }^{1} \mathrm{D}\right) 5 s$ ${ }^{2} \mathrm{D}_{21 / 2}$ levels were found in $\mathrm{Zn}$ II, and a few other additions and revisions are given for the analysis. The combinations of the new levels $3 d^{9}\left({ }^{2} \mathrm{D}\right) 4 s 4 p\left({ }^{3} \mathrm{P}^{\circ}\right){ }^{4} \mathrm{~F}_{41 / 2}^{\circ}$ in $\mathrm{Zn}$ II and $4 d^{9}\left({ }^{2} \mathrm{D}\right) 5 s 5 p\left({ }^{3} \mathrm{P}^{\circ}\right){ }^{2} \mathrm{~F}_{21 / 2}^{\circ}$ in $\mathrm{Ag} \mathrm{I}$ are also listed.

Key words: Atomic spectra; energy levels; silver; zinc.
\end{abstract}

\section{Introduction}

A recent fitting of some $d^{9} s p$ configurations to intermediate coupling theory provided useful comparisons of experimental with predicted levels in several spectra [1]. ${ }^{1}$ We also made similar calculations for Zn II $3 d^{9} 4 s 5 s$ and $\mathrm{Ag}$ I $4 d^{9} 5 s 6 s$. The results of these $d^{9} s s$ calculations are reported here, along with the supporting combinations for a few new or revised level positions found during the course of the $d^{9} s p$ and $d^{9} s s$ work. Some new wavelength measurements for ZnII in the vacuum ultraviolet, and redetermined energy level positions based partially on these measurements, are given in an accompanying paper [2].

\section{Zn II}

Our first few energy-matrix diagonalization and levelfitting iterations [1] for Zn II $3 d^{9} 4 s 4 p$ indicated that the position previously listed [3] for ${ }^{4} \mathrm{~F}_{4}^{\circ}$ was incorrect. A search with Dick's [4] line list yielded the new level and combinations for ${ }^{4} \mathrm{~F}_{4 \frac{1}{2}}^{\circ}$ shown in table 1. The line at $54538.3 \mathrm{~cm}^{-1}$ arising from $4 p^{\prime}{ }^{4} \mathrm{~F}_{41}^{\circ}-5 s^{\prime}{ }^{4} \mathrm{D}_{3 \frac{1}{2}}$ was apparently not resolved on Dick's plates from a line at $54541.1 \mathrm{~cm}^{-1}\left(4 s^{2}{ }^{2} \mathrm{D}_{21}-4 f^{2} \mathrm{~F}^{\circ}\right)$. The quoted wavenumbers are from new observations [2] where the two lines are well resolved and show different excitation characteristics, each proper for the assigned classification.

Figures in brackets indicate the literature references at the end of this paper.
The $3 d^{9} 4 s\left({ }^{3} \mathrm{D}\right) 5 s^{2} \mathrm{D}_{21 / 2}$ level at $164998.9 \mathrm{~cm}^{-1}$ in table 1 also replaces a previous level that did not fit the calculation. The results of fitting intermediate coupling theory ${ }^{2}$ to $\mathrm{Zn}$ II $3 d^{9} 4 s 5 s$ are given in tables 2 and 3 . The five parameter values in table 3 are determined by only seven known levels. It is seen, however, that these values scale well with the corresponding values ${ }^{3}$ for $\mathrm{Cu}$ I $3 d^{9} 4 s 5 s$ where all eight levels are known. A check on the value of $\mathrm{G}_{2}(3 d, 4 s)$ for $\mathrm{Zn} \mathrm{II} \mathrm{is} \mathrm{given} \mathrm{by} \mathrm{the} \mathrm{fact} \mathrm{that} \mathrm{it} \mathrm{is} \mathrm{only} \mathrm{slightly}$ less that the value $1914 \mathrm{~cm}^{-1}$ for $\mathrm{Zn}$ III $3 d^{9} 4 \mathrm{~s}$. The presence of the $5 \mathrm{~s}$ electron has little effect on the $3 d-4 s$ interaction, in agreement with a similar comparison of these two configurations in $\mathrm{Cu}$ I and $\mathrm{Cu}$ II, respectively.

The $3 d^{9} 4 s\left({ }^{1} \mathrm{D}\right) 5 s{ }^{2} \mathrm{D}_{2 \frac{1}{2}}$ level in table 2 was also found by searching near the position predicted in earlier diagonalizations. Some combinations of this new level are given in table 1 .

${ }^{2}$ The $d^{9} s s$ energy matrices were calculated independently for this work. They include an additive constant $A$, related to the configuration center of gravity (c.g.) as follows:

$$
A=(\text { c.g. })+\frac{1}{2}\left[G_{2}(d s)+\mathrm{G}_{2}^{\prime}(d s)+\mathrm{G}_{0}(s s)\right] .
$$

A description of the procedure for least-squares fitting of level positions to obtain energy parameter values is given by Racah [5]. We use the term "rms error" to describe the level fits. This is defined as

$$
\left[\left(\sum_{i=1}^{N} \delta_{i}^{2}\right) /(N-M)\right]^{1 / 2}
$$

where $\delta$ is the difference between the experimental and calculated level positions, $N$ is the number of experimental levels entered into the fitting procedure, and $M$ is the number of free parameters.

${ }^{3}$ Our fitted values for the CuI parameters are in agreement with those recently published by Wilson [6]. 
TABLE 1. Combinations of some $\mathrm{Zn}$ II levels


in parentheses are from [2], and the others are from [4].

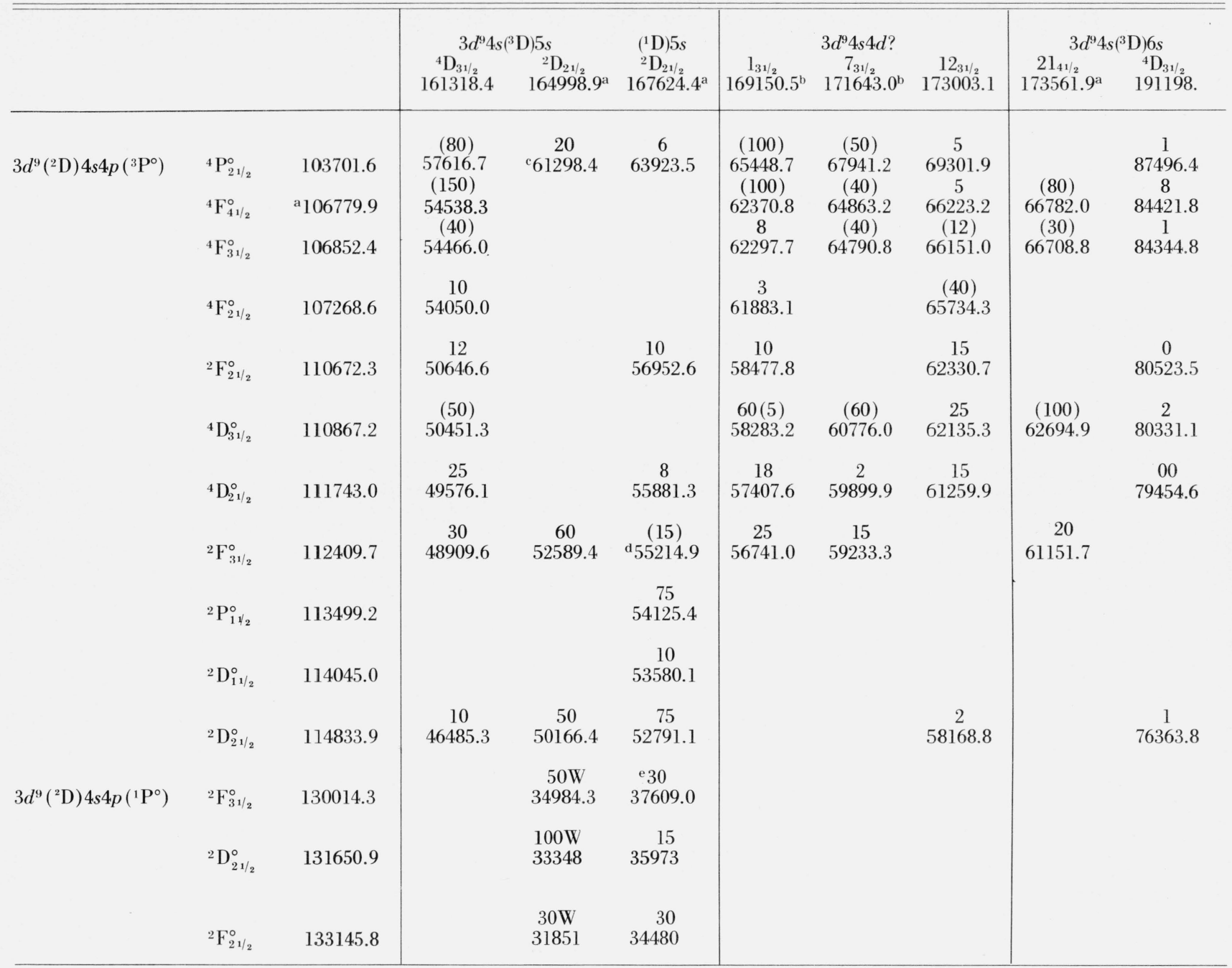

a New level.

b J-value of level changed here.

c Line also classified by another transition [3].

${ }^{d}$ Line newly resolved from stronger neighboring line [2]

e Line also classified by $\mathrm{Zn}$ III transition [4].

TABLE 2. Calculated energy levels for $\mathrm{Zn}$ II $3 \mathrm{~d}^{9} 4 \mathrm{~s} 5 \mathrm{~s}$

The last column gives the percentage of the leading eigenvector component in the scheme of the first column.

\begin{tabular}{|c|c|c|c|c|c|}
\hline Term & $J$ & $\begin{array}{l}\text { Experimental } \\
\mathrm{cm}^{-1}\end{array}$ & $\begin{array}{c}\text { Calculated } \\
\mathrm{cm}^{-1}\end{array}$ & $\begin{array}{l}\mathrm{E}-\mathrm{C} \\
\mathrm{cm}^{-1}\end{array}$ & $\begin{array}{l}L S \\
\%\end{array}$ \\
\hline $3 d^{9} 4 s\left({ }^{3} \mathrm{D}\right) 5 s^{4} \mathrm{D}$ & $\begin{array}{l}3^{1 / 2} \\
2^{1 / 2} \\
1^{1 / 2} \\
0^{1 / 2}\end{array}$ & $\begin{array}{l}161318 \\
162070 \\
162897 \\
164070\end{array}$ & $\begin{array}{l}161322 \\
162068 \\
162892 \\
164070\end{array}$ & $\begin{array}{r}-4 \\
2 \\
5 \\
0\end{array}$ & $\begin{array}{r}100 \\
85 \\
74 \\
100\end{array}$ \\
\hline$\left({ }^{3} \mathrm{D}\right) 5 s^{2} \mathrm{D}$ & $\begin{array}{l}2^{1 / 2} \\
1^{1 / 2}\end{array}$ & $\begin{array}{l}164999 \\
165277\end{array}$ & $\begin{array}{l}164999 \\
165279\end{array}$ & $\begin{array}{r}0 \\
-2\end{array}$ & $\begin{array}{l}88 \\
46\end{array}$ \\
\hline ( $\left.{ }^{1} \mathrm{D}\right) 5 s^{2} \mathrm{D}$ & $\begin{array}{l}2^{1 / 2} \\
11 / 2\end{array}$ & 167624 & $\begin{array}{l}167624 \\
169268\end{array}$ & 0 & $\begin{array}{l}92 \\
57\end{array}$ \\
\hline
\end{tabular}

TABLE 3. Energy parameter values for three $\mathrm{d}^{9} \mathrm{msns}$ configurations Unit is $\mathrm{cm}^{-1}$

\begin{tabular}{|c|c|c|c|}
\hline & $\begin{array}{c}\mathrm{Zn} \text { II } \\
3 d^{9} 4 s 5 s\end{array}$ & $\begin{array}{c}\mathrm{Cu} \text { I } \\
3 d^{9} 4 s 5 s\end{array}$ & $\begin{array}{c}\mathrm{Ag} \mathrm{I} \\
4 d^{9} 5 s 6 s\end{array}$ \\
\hline $\begin{array}{c}A \\
\mathrm{G}_{2}(d, m s) \\
\mathrm{G}_{2}^{\prime}(d, n s) \\
\mathrm{G}_{0}(m s, n s) \\
\zeta_{d} \\
\text { rms error }{ }^{2}\end{array}$ & $\begin{array}{r}166409.6 \pm 4 \\
1884.8 \pm 4 \\
291.4 \pm 4 \\
1812.0 \pm 6 \\
1099.1 \pm 3 \\
5\end{array}$ & $\begin{array}{r}65964.3 \pm 3 \\
1550.0 \pm 3 \\
158.9 \pm 3 \\
1021.9 \pm 3 \\
826.0 \pm 2 \\
4\end{array}$ & $\begin{array}{r}84199.3 \pm 20 \\
1874 \pm 102 \\
197.5 \pm 27 \\
886 \pm 19 \\
1818 \pm 10 \\
25\end{array}$ \\
\hline
\end{tabular}




\section{Ag I}

The $4 d^{9} 5 s 6 s$ configuration in this atom begins 18306 $\mathrm{cm}^{-1}$ above the $\mathrm{Ag}$ II $\left(4 d^{10}{ }^{1} \mathrm{~S}\right)$ limit. The levels having $J=1 \frac{1}{2}$ or $2 \frac{1}{2}$ are thus broadened by autoionization into the $4 d^{10} \epsilon d^{2} \mathrm{D}$ continuum. This mixing with the continuum may help account for the larger standard errors on the parameter values we obtained for Ag I $4 d^{9} 5 s 6 s$ (table 3 ). The same seven levels are known experimentally as for $\mathrm{Zn}$ II, but the level rms error is $25 \mathrm{~cm}^{-1}$ for $\mathrm{Ag}$ I. The value for the Ag I parameter with the largest standard error, $\mathrm{G}_{2}(4 d, 5 s)=1874 \pm 102$ $\mathrm{cm}^{-1}$, compares well with the Ag II value $1942 \mathrm{~cm}^{-1}$ obtained directly from the experimental levels of $4 d^{9} 5 s$. Both values may be affected by neglect of configura- tion interaction, since the $A g$ II value for $G_{2}$ given by a general treatment [7] of $(4 d+5 s)^{n}$ is $2045 \pm 17$ $\mathrm{cm}^{-1}$.

The calculated levels are given in table 4. On inspection of the experimental levels, we noticed that whereas the $4 d^{9} 5 s\left({ }^{3} \mathrm{D}\right) 6 s^{2} \mathrm{D}$ and ${ }^{4} \mathrm{D}$ terms overlap badly, the levels appeared to fall into separated terms based on the coupling scheme $\left[\left(d^{9}\right) J_{I},(s s) J_{I I}\right] J$. As may be seen in table 4 , the latter scheme is indeed more appropriate than $L S$ coupling. The $J_{I} J_{I I}$ percentage compositions were obtained by a transformation from the $\left(d^{9} s\right) s L S$ scheme of our matrices. ${ }^{4}$ For those six levels having coupling-dependent purity, the average purity in $J_{I} J_{I I}$ coupling is 82 percent, as compared with 62 percent in the $L S$ scheme.

TABLE 4. Calculated energy levels for $\mathrm{Ag} I \mathrm{I} 4 \mathrm{~d}^{9} 5 \mathrm{~s} 6 \mathrm{~s}$

The largest component in each of the two coupling schemes is given for each level.

\begin{tabular}{|c|c|c|c|c|c|c|c|}
\hline$\left[\left(4 d^{9}\right) J_{\mathrm{I}},(5 s 6 s) J_{\mathrm{II}}\right]$ & $J$ & $\begin{array}{l}\text { Experimental } \\
\mathrm{cm}^{-1}\end{array}$ & $\begin{array}{l}\text { Calculated } \\
\mathrm{cm}^{-1}\end{array}$ & $\begin{array}{l}\mathrm{E}-\mathrm{C} \\
\mathrm{cm}^{-1}\end{array}$ & $\underset{\%}{J_{1} J_{\mathrm{II}}}$ & Term & $\begin{array}{r}L S \\
\%\end{array}$ \\
\hline$\left[2^{1 / 2}, 1\right]$ & $\begin{array}{l}31 / 2 \\
21 / 2 \\
1 / 2\end{array}$ & $\begin{array}{l}79413 \\
80164 \\
81266\end{array}$ & $\begin{array}{l}79424 \\
80175 \\
81242\end{array}$ & $\begin{array}{r}-11 \\
-11 \\
24\end{array}$ & $\begin{array}{r}100 \\
84 \\
87\end{array}$ & $\begin{array}{r}4 d^{9} 5 s\left({ }^{3} \mathrm{D}\right) 6 s{ }^{4} \mathrm{D} \\
{ }^{4} \mathrm{D} \\
{ }^{4} \mathrm{D}\end{array}$ & $\begin{array}{r}100 \\
65 \\
48\end{array}$ \\
\hline$\left[2^{1 / 2}, 0\right]$ & $2 \frac{1}{2}$ & 82070 & 82066 & 4 & 79 & $4 d^{9} 5 s\left({ }^{3} \mathrm{D}\right) 6 s^{2} \mathrm{D}$ & 68 \\
\hline$\left[1 \frac{1 / 2}{1}, 1\right]$ & $\begin{array}{l}0^{1 / 2} \\
11 / 2 \\
2^{1 / 2}\end{array}$ & $\begin{array}{l}83983 \\
84594 \\
86484\end{array}$ & $\begin{array}{l}83969 \\
84606 \\
86490\end{array}$ & $\begin{array}{r}14 \\
-12 \\
-6\end{array}$ & $\begin{array}{r}100 \\
79 \\
82\end{array}$ & $\begin{array}{l}4 d^{9} 5 s\left({ }^{3} \mathrm{D}\right) 6 s^{4} \mathrm{D} \\
{ }^{4} \mathrm{D}^{\mathrm{a}} \\
4 d^{9} 5 s\left({ }^{1} \mathrm{D}\right) 6 s^{2} \mathrm{D}\end{array}$ & $\begin{array}{r}100 \\
49 \\
81\end{array}$ \\
\hline$\left[1^{1 / 2}, 0\right]$ & $1^{1 / 2}$ & & 87429 & & 81 & $4 d^{9} 5 s\left({ }^{1} \mathrm{D}\right) 6 s^{2} \mathrm{D}$ & 64 \\
\hline
\end{tabular}

a The $L S$ name for this level would be $\left({ }^{3} \mathrm{D}\right)^{2} \mathrm{D}$, which comprises 41 percent of the calculated composition.

The $J_{\mathrm{I}} J_{\mathrm{II}}$ term structure of this configuration is apparent in figure 1 . There is no overlapping of the four terms, and the largest of the interactions contributing to the structure, the $4 d^{9}$ spin-orbit interval $2 \frac{1}{2} \zeta_{d}$, is nicely exhibited.

As a result of our calculations [1] for $A g$ I $4 d^{95} 55 p$ we found a new level $4 d^{9}\left({ }^{2} \mathrm{D}\right) 5 s 5 p\left({ }^{3} \mathrm{P}^{\circ}\right){ }^{2} \mathrm{~F}_{21}^{\circ}$ (designated $\left.5 p^{\prime}{ }^{2} \mathrm{~F}_{2 !}^{\circ}\right)$. Five combinations are given in table 5 for this level, three of the lines not having been previously classified [8]. The character of these lines shows the level to be wide, as expected because of autoionization. The circumstance that its strongest expected transition, to $4 d^{9} 5 s^{2}{ }^{2} \mathrm{D}_{11 / 2}$, is masked by the much stronger resonance line at $3382.89 \AA$ probably explains previous failure to find this level. Some other results of the $4 d^{9} 5 s 5 p$ work as it affected line classifications are also given in table 5 . The levels of $4 d^{9} 5 s 6 s$ are given $L S$ names in this table to make it consistent with Shenstone's full line list.
4 This transformation was actually accomplished by first diagonalizing the matrices with all parameters zero except $\zeta_{t}$ and $\mathrm{G}_{0}(s)$. See [5].

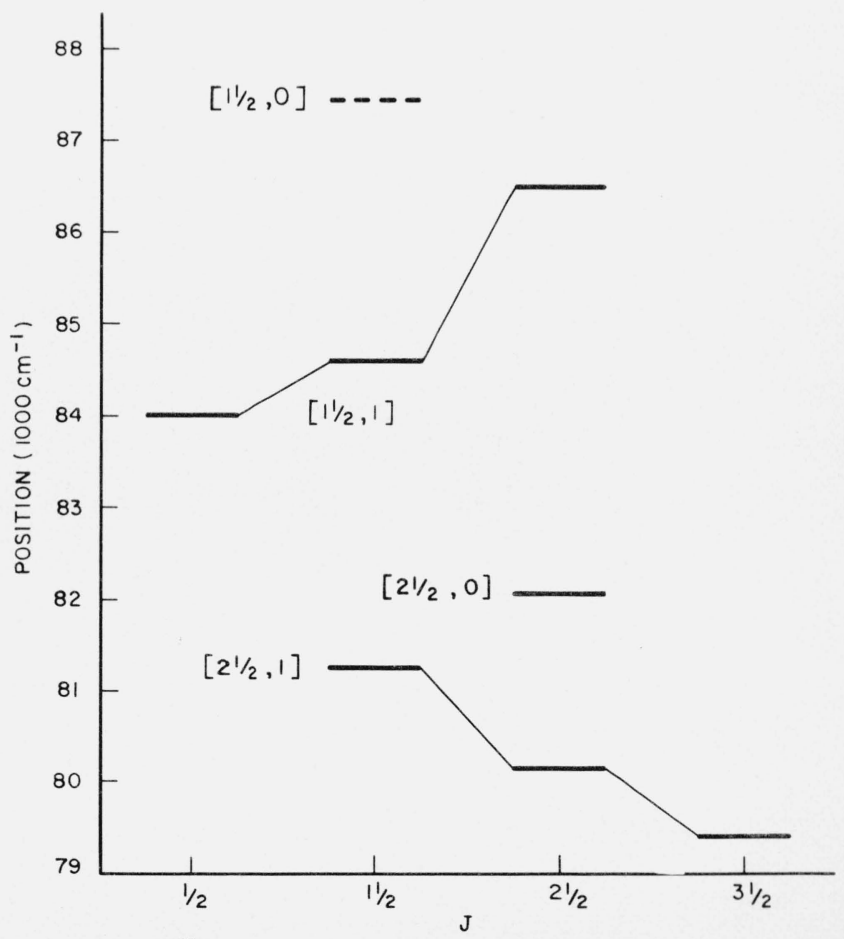

Figure 1. Energy levels of $\mathrm{Ag}$ I $4 d^{9} 5 \mathrm{~s} 6 \mathrm{~s}$.

The connected levels form terms in the $\left[\left(4 d^{9}\right) J_{1},(5 s 6 s) J_{11}\right] J$ coupling scheme appropriate for this configuration. The $\left[1 \frac{1}{2}, 0\right]$ level has not been observed. 
TABLE 5. Classifications of some Ag I lines

Wavelengths and intensities are from Shenstone [8]. Configurations and parentages for the levels are indicated by use of the designation scheme of AEL [8]. Notes:

A. Name of the $4 d^{9} 5 s 5 p$ level involved in transition was changed in [1].

B. Line was previously listed as doubly classified, with one of the transitions belonging to the now rejected level at $62934 \mathrm{~cm}^{-1}$

C. New classification.

\begin{tabular}{|c|c|c|c|c|}
\hline$\lambda(\underset{\AA}{\text { air }})$ & Int. $^{a}$ & $\begin{array}{c}\sigma(\mathrm{vac}) \\
\mathrm{cm}^{-1}\end{array}$ & Classification & Note \\
\hline 6010.1 & $5 \mathrm{U}$ & 16634. & $5 p^{\prime 2} \mathrm{D}_{11 / 2}^{\circ}-6 s^{\prime}{ }^{4} \mathrm{D}_{21 / 2}$ & A \\
\hline 5801.92 & $5 \mathrm{U}$ & 17230.9 & $5 p^{\prime}{ }^{4} \mathrm{D}_{21 / 2}^{\circ}-6 s^{\prime}{ }^{4} \mathrm{D}_{31 / 2} ?^{\mathrm{b}}$ & $\mathrm{B}$ \\
\hline 5637.01 & $5 \mathrm{U}$ & 17735.0 & $5 p^{\prime 2} \mathrm{D}_{11 / 2}^{\circ}-6 s^{\prime}{ }^{4} \mathrm{D}_{11 / 2}$ & A \\
\hline 4917.5 & $10 \mathrm{UU}$ & 20330 . & $5 p^{\prime}{ }^{2} \mathrm{~F}_{21 / 2}^{\circ}-6 s^{\prime}{ }^{2} \mathrm{D}_{11 / 2}$ & C \\
\hline 4888.21 & & 20451.7 & $5 p^{\prime}{ }^{2} \mathrm{D}_{11 / 2}^{\circ}-6 s^{\prime}{ }^{4} \mathrm{D}_{1 / 2}$ & A \\
\hline 4745.93 & $2 \mathrm{U}$ & 21064.8 & $5 p^{\prime}{ }^{2} \mathrm{D}_{11 / 2}^{\circ}-6 s^{\prime}{ }^{2} \mathrm{D}_{11 / 2}$ & A \\
\hline 4615.69 & $30 \mathrm{U}$ & 21659.2 & $5 p^{\prime}{ }^{4} \mathrm{P}_{11 / 2}^{\circ}-6 s^{\prime}{ }^{4} \mathrm{D}_{21 / 2}$ & B \\
\hline 4499.50 & $1 \mathrm{U}$ & 22218.5 & $5 p^{\prime 2} \mathrm{~F}_{21 / 2}^{\circ}-6 s^{\prime \prime}{ }^{2} \mathrm{D}_{21 / 2}$ & C \\
\hline 4354.7 & $5 \mathrm{UU}$ & 22957. & $\left\{\begin{array}{l}5 p^{\prime}{ }^{2} \mathrm{~F}_{31 / 2}^{\circ}-17 \\
5 p^{\prime}{ }^{2} \mathrm{~F}_{21 / 2}^{\circ}-14_{21 / 2}^{\circ}\end{array}\right.$ & C \\
\hline 3542.608 & 50 & 28219.76 & $5 p^{\prime}{ }^{4} \mathrm{~F}_{41 / 2}^{\mathrm{o}}-12 ?^{\mathrm{b}}$ & B \\
\hline 3469.16 & 30 & 28817.2 & $\begin{array}{l}5 s^{2}{ }^{2} \mathrm{D}_{11 / 2}-5 p^{\prime}{ }^{2} \mathrm{D}_{11 / 2}^{\circ} \\
5 s^{2} S_{1 /}-5 p{ }^{2} \mathrm{P}^{\circ}\end{array}$ & A \\
\hline 3382.893 & $1000 \mathrm{R}$ & 29552.04 & $\left\{\begin{array}{lll}5 s & \mathrm{~S}_{1 / 2}-5 p & 1 / 2 \\
5 s^{2}{ }^{2} \mathrm{D}_{11 / 2}-5 p^{\prime}{ }^{2} \mathrm{~F}_{21 / 2}^{\circ}\end{array}\right.$ & C \\
\hline 2938.42 & $20 \mathrm{U}$ & 34022. & $5 s^{2}{ }^{2} \mathrm{D}_{21 / 2}-5 p^{\prime}{ }^{2} \mathrm{~F}_{21 / 2}^{\circ}$ & $\mathrm{C}$ \\
\hline $\begin{array}{r}\lambda(\mathrm{vac}) \\
1574.02\end{array}$ & 5 & 63531.6 & $5 s \quad{ }^{2} \mathrm{~S}_{1 / 2}-5 p^{\prime}{ }^{2} \mathrm{D}_{11 / 2}^{\circ}$ & A \\
\hline 1507.37 & $50 \mathrm{RUU}$ & 66341. & $5 s \quad{ }^{2} \mathrm{~S}_{1 / 2}-5 p^{\prime}{ }^{4} \mathrm{D}_{11 / 2}^{\circ}$ & A \\
\hline
\end{tabular}

a The letter " $U$ " was used in [8] for wide lines (German unscharf).

b Classification given as questionable by Shenstone [8]' The strong line at $3542.6 \AA$ does not have the wide character expected for transitions from the autoionizing $5 p^{\prime}{ }^{2} \mathrm{~F}_{2}^{\circ}$ level No classification has been found for this line except that given. (The three combinations of the even level 12 of Shenstone were given with question marks, so presumably the level itself was considered doubtful.)

\section{References}

[1] Martin, W. C., and Sugar, J., J. Opt. Soc. Am.

[2] Martin, W. C., and Kaufman, V., J. Res. Nat. Bur. Stand. (U.S.), 74A, No. 1, 11 (Jan.-Feb. 1970).

[3] Crooker, A. M., and Dick, K. A., Can. J. Phys. 46, 1241 (1968).

[4] Dick, K. A., The Spark Spectra of Zinc (Ph. D. Thesis, University of British Columbia, 1966).

[5] Racah, G., Bull. Res. Council Israel 8F, No. 1, 1 (1959).

[6] Wilson, M., J. Phys. B2, 524 (1969).

[7] Shadmi, Y., Bull. Res. Council Israel 9F, 141 (1961).

[8] Shenstone, A. G., Phys. Rev. 57, 894 (1940). See also C. E. Moore, Atomic Energy Levels, Nat. Bur. Stand. (U.S.), Circ. 467, Vol. III, 282 pages (1958). 